\title{
The Influence of Slopes of Isolated Three-Dimensional Valleys on Near-Surface Turbulence
}

\author{
Sylvio Freitas ${ }^{1}$ (D) Frank Harms $^{1} \cdot$ Bernd Leitl $^{1}$
}

Received: 4 December 2020 / Accepted: 30 June 2021 / Published online: 27 July 2021

(C) The Author(s) 2021

\begin{abstract}
Motivated by a limited understanding of how valleys affect near-surface turbulence, characterizations of neutrally stable atmospheric-boundary-layer flows over isolated valleys are presented. In particular, the influence of the slopes of the three-dimensional ridges that form the idealized valleys are investigated. Flows over three distinct symmetric valley geometries were modelled in a large boundary-layer wind tunnel. For each valley geometry, the high-resolution measurements from the crests of each of the ridges and the midpoint between them are compared with an undisturbed moderately rough classed boundary-layer flow over flat terrain with homogeneous surface roughness. Flow separation originates above the crests of the first ridges of all geometries and generates recirculation zones. These are characterized by slope-dependent increases in three-dimensional nearsurface turbulence when compared with the attached flows further upstream. The recirculation zones longitudinally extend to roughly half the valley width. Above the crests of the second ridges, the longitudinal velocity component decreases and turbulence intensity increases when compared with the flows above the crests of the first ridges. Results also exhibit significant increases of turbulence above the inner-valley regions of all geometries.
\end{abstract}

Keywords Complex terrain $\cdot$ Idealized valleys $\cdot$ Physical modelling $\cdot$ Slope-inclination effects $\cdot$ Turbulence characterizations

\section{Introduction}

It is well established that complex terrain affects local meteorology and its impacts are most evident within the lower atmospheric boundary layer (ABL). This influences a wide variety of applications, such as wind engineering and air quality. Early predictions of flows over orography were motivated by the linear theory of Jackson and Hunt (1975), which is most applicable for attached flows over gentle-sloped two-dimensional hills. Since then, the focus of the majority of studies of flow over orography has been on expressing speedups above the crests of isolated hills or ridges for wind-energy harvesting. Less emphasis

Bernd Leitl

bernd.leitl@uni-hamburg.de

1 Meteorological Institute, Centre for Earth System Research and Sustainability, University of Hamburg, Bundesstrasse 55, 20146 Hamburg, Germany 
has been given to quantifications of the turbulence characteristics of the respective flows. Particularly above locations downwind from the crests of single hills, such as leeside slopes or their downwind vicinities, flow characterizations are frequently overlooked. This contributes to a lack of understanding of the effects of orography on the turbulence of nearsurface $\mathrm{ABL}$ flow and further investigations are required.

Field campaigns provide the most reliable measurements for flows over complex terrain. These are limited by high costs and complex logistics, as well as the inability to control flow conditions at the measurement sites. Moreover, finding real sites of isolated terrain features, with well-defined inflow characteristics, constitutes a major challenge. Consequently, a small number of field campaigns has been conducted over the last decades. Those taking place at Askervein hill in the Scottish Hebrides (Taylor and Teunissen 1987), and Bolund hill in Denmark (Bechmann et al. 2009), remain the most widely studied. Recently, the largest field campaign to date was carried out in an isolated valley in Perdigão, Portugal, in the scope of the New European Wind Atlas (Mann et al. 2017; Fernando et al. 2019).

Numerical simulation is the main modelling tool applied to flows over orography. The integration of computational fluid dynamics (CFD) has become common for characterizations of microscale ABL flows over orography. Computational fluid dynamics is particularly advantageous in resolving turbulence characteristics that are neglected or oversimplified in linear models. As exemplified by numerical simulations of the flows over Bolund hill, simulation data continue to show significant disagreements with experimental data close to the surface and in quantifications of turbulence properties (e.g., Bechmann et al. 2011; Chaudhari et al. 2016; Conan et al. 2016). Time-averaged Reynolds-averaged Navier-Stokes (RANS) remains the most widely applied CFD approach for flows over orography (e.g., Loureiro et al. 2007; Blocken et al. 2015). However, time-dependent largeeddy simulation has become the main approach used in the last few decades (e.g., Vuorinen et al. 2015; Liu et al. 2016), but such simulations of flows over orography have failed to provide significant improvements over RANS approaches (e.g., Bechmann et al. 2011; Abdi and Bitsuamlak 2014).

One of the main drivers for the loss of accuracy of numerical models at low altitudes above orography is the lack of validation data from experiments. This is not only restricted by the scarcity of field campaigns but also by the available experimental data lacking high enough spatial and temporal resolutions to match the ever-growing computational capabilities. These increases lead to higher numerical grid resolutions, but the smaller surface heterogeneities also become more influential on the results. This gap can be partially addressed through physical modelling, which enables maximal control of the inflow characteristics and has no requirement for additional turbulence modelling. Large size distributions of turbulent eddies are generated directly and only constrained by the scales of the modelled ABL flows.

Isolated hills or ridges constitute the most common terrain features investigated in wind tunnels. Initiatives related to real terrain structures have been mainly centred on modelling the flows over Bolund (e.g., Yeow et al. 2015; Conan et al. 2016) and Askervein (e.g., Teunissen et al. 1987). Characterizations of flows over real terrain provide the most accurate data for the site-specific landforms but lack transferability to other terrain features of the same type. The majority of wind-tunnel studies have focused on idealized two-dimensional single hills of infinite width (e.g., Takahashi et al. 2002; Ayotte and Hughes 2004; Cao and Tamura 2007). This has limitations due to the wind-tunnel sidewalls that can create unrealistic lateral flow phenomena. Furthermore, air in flow with insufficient kinetic energy to overcome the terrain 
features become entrapped upstream of the terrain or are unrealistically advected over the terrain, which leads to overestimates of speed-up (Meroney 1990).

Idealized geometries represent a simplified counterpart of more complex systems and allow less influential geometric parameters to be neglected from the modelling process. The lack of site-specific details, which are required for real terrain structures, provides maximal data transferability between equivalent terrain types. This is particularly useful in ascertaining how individual geometric parameters of the terrain, such as slopes or heights, affect nearsurface ABL flows. Furthermore, idealized geometries enable variable flow scales without the requirement of replicating site-specific flow conditions. Idealized single landforms consist of simple geometries and small study domains, which are also beneficial in providing validation data for numerical models (Kempf 2008).

Investigations focused on flows over isolated valleys or double ridges are scarce when compared with studies centred on single hills or ridges (Finnigan et al. 2020). The field campaign at Perdigão has provided analysis of specific properties of the flow (e.g., Menke et al. 2018, 2019; Fernando et al. 2019; Letson et al. 2019). Menke et al. (2019) studied the lengths of recirculation zones under different atmospheric stabilities and observed that recirculation mainly took place within the valley for neutrally stable flows, extending on average to the valley centre. Previous studies performed in wind tunnels investigated flows over two-dimensional valleys that consisted of depressions in flat terrain (e.g., Snyder et al. 1991; Garvey et al. 2005). Snyder et al. (1991) evaluated flows above three idealized two-dimensional geometries of constant depth $(H)$ and varying inner valley slopes $\left(10^{\circ}, 16^{\circ}\right.$, and $\left.26^{\circ}\right)$. Flow separation originated at the upstream edge of the steepest slope, forming a steady recirculation zone that extended beyond the valley centre to a longitudinal distance of almost $0.75 \mathrm{H}$. Maximal longitudinal velocity fluctuations and shear were found atop of the steep-sloped valley. In a similar investigation, Garvey et al. (2005) studied the flow over a two-dimensional valley with a $27^{\circ}$ slope for two inflow directions $\left(0^{\circ}\right.$ and $\left.45^{\circ}\right)$. Flow separation was observed, with the resulting recirculation zone extending to just under $70 \%$ of the inner valley length for the $0^{\circ}$ inflow direction.

The present investigation constitutes a small part of a larger research project aimed at evaluating the effects of complex terrain on near-surface turbulence. Data requirements were ascertained through workshops for scientists and specialists working in the field of flow over complex terrain. Varying geometries of isolated terrain features and measurement locations rarely characterized in the literature were the main requisites proposed by the attendees. In particular, geometries that promoted flow separation and the formation of recirculation zones were major requisites. Accordingly, the effects of three isolated three-dimensional valleys with three distinct slopes $\left(10^{\circ}, 30^{\circ}\right.$, and $\left.75^{\circ}\right)$, constant depths $(H)$, and widths $(A=12 H)$ were analyzed through physical modelling in a large boundary-layer wind tunnel. In order to evaluate the effects of the slopes on the flows, analyses are mainly centred on time-averaged turbulence properties at three equivalent locations above each of the idealized valleys and compared with undisturbed flows above flat terrain. The experimental set-up is detailed in Sect. 2 and includes descriptions of the valley geometries, the boundary-layer wind tunnel, and measurement techniques. Results of the flows above the flat terrain and the valleys are presented in Sect. 3, and the flow characteristics discussed in Sect. 4. Relevant conclusions are given in Sect. 5. 


\section{Methodology}

Experiments were performed in the Wotan wind-tunnel facility of the Environmental Wind-tunnel Laboratory (EWTL) of the University of Hamburg. With a test-section length of $18 \mathrm{~m}$, width of $4 \mathrm{~m}$, and an adjustable ceiling height ranging between 2.75 and $3.25 \mathrm{~m}$, Wotan is the largest of the EWTL wind tunnels. Wotan has no heating capabilities, thus no buoyancy effects are generated and the modelled ABL flows are neutrally stable.

\subsection{Experimental Set-Up}

Thirty-one isosceles-shaped spires (of height $27 \mathrm{~cm}$ ) located at the start of the test section were used to create larger turbulent structures of the modelled ABL flow. This was followed by a fetch of approximately $10.5 \mathrm{~m}$ built up of roughness elements to generate the smaller near-surface turbulence structures of the flow. Roughness elements consisted of longitudinally equidistant rows of brass chains with two alternating diameters (4 and $6 \mathrm{~mm}$ ). Above the model section, with an approximate length of $7.5 \mathrm{~m}$, a flat homogeneous surface built of three-dimensional pyramids of height $1.2 \mathrm{~mm}$ maintained constant roughness characteristics between the inflow section and the wind-tunnel outlet. This ensured flow continuity and inhibited the generation of unrealistic internal boundary layers. The homogeneous surface also constituted a reference flat terrain scenario for comparative assessments of the effects of the valleys on the flows, with the corresponding data represented by grey gradient symbols in the plots of Sect. 3. All surfaces were painted black to minimize the backscatter of laser light which can cause anomalous readings.

Correlated flow velocity measurements were made with a Prandtl tube and a laserDoppler velocimeter with a two-dimensional fibre-optic probe (of diameter $27 \mathrm{~cm}$ ) and an F80 Burst Spectrum Analyzer (BSA) equipped with BSA software version 4.50.03 (Dantec Dynamics, Skovlunde, Denmark). The former was used for sampling reference longitudinal velocity components $\left(U_{0}\right)$ and the latter for high-resolution measurements above the valley models. All measurements were performed in the Cartesian (or Earth-referenced) flow coordinate system and employed filtered transit-time weighting. The reproducibility (or data uncertainty) of the measurement data was quantified through several repetitive measurements carried out above each analysis position on different days and is expressed by error bars in the plots presented in Sect. 3.

The experimental set-up ensured minimal flow blockages, verified via the geometric cross-sectional blockage and the gradients of longitudinal static pressure. Valley geometries fulfilled blockage criteria, while geometric blockages $(\leq 3 \%)$ and pressure gradients $(\leq 4 \%)$ were below the $5 \%$ thresholds stated in VDI (2000). Lateral symmetry of the modelled ABL flow was verified for time-averaged dimensionless longitudinal velocity components $\left(\overline{U / U_{0}}\right)$ and velocity fluctuations $\left(\overline{\sigma_{U} / U_{0}}\right)$ above 10 equidistant spanwise locations $(\Delta y=200 \mathrm{~mm})$. Small lateral inhomogeneities inherent to the wind-tunnel facility were observed, with a maximum difference of $\approx 5 \%$ to the average $\overline{U / U_{0}}$ being found at $y=600 \mathrm{~mm}$ from the centreline.

\subsection{Flow Similarity}

For the present microscale ABL flow, where the effects of Coriolis forces and buoyancy are negligible, similarity between full and model-scale flows is a question of Reynolds number $(R e)$ independence (Townsend 1956), which was verified for $\overline{U / U_{0}}$ and $\overline{\sigma_{U} / U_{0}}$ 
at $z / H=0.63$. Accordingly, flow similarity was obtained when differences between each parameter were contained within a $2 \%$ bandwidth of the corresponding mean values, first occurring for freestream flow speeds starting at $\approx 3 \mathrm{~m} \mathrm{~s}^{-1}$. A value of $\approx 5 \mathrm{~m} \mathrm{~s}^{-1}$ was used for the present experiments and resulted in a corresponding turbulence intensity of $\approx 5 \%$. Under these freestream flow conditions, $R e \approx 3 \times 10^{4}$, which corresponds to a fully turbulent ABL flow according to the criterion $\left(R e \geq 1 \times 10^{4}\right)$ proposed by Snyder (1981).

\subsection{Valley Geometries}

Idealized symmetric three-dimensional valley geometries of constant width $(A=12 H)$ were built from combinations of two equivalent three-dimensional ridges with constant height $(H)$ of $8 \mathrm{~cm}$ and spanwise width of $1.8 \mathrm{~m}$. Two ridge geometries (one symmetric and one non-symmetric) provided three distinct inclinations of the windward slopes of the ridges used to build three distinct valley geometries: $10^{\circ}, 30^{\circ}$ (symmetric ridge), and $75^{\circ}$. The idealized valley geometries are schematized in Fig. 1 and named according to the windward slope inclinations of the first ridges. The corresponding horizontal lengths of each of the slopes (or half-lengths) were $45 \mathrm{~cm}\left(10^{\circ}\right.$ slope), $14 \mathrm{~cm}\left(30^{\circ}\right)$, and $2.5 \mathrm{~cm}\left(75^{\circ}\right)$. All geometries were aligned normal to the main flow direction ( $U$ in Fig. 1). Model surfaces were built of identical three-dimensional pyramids to that of the flat terrain.

\subsection{Analysis Positions}

Flow properties were sampled above the centreline of the spanwise symmetry plane $(\approx 2 \mathrm{~m}$ from the wind-tunnel side walls) above the crests of each of the ridges, hereby designated crest 1 and crest 2, and above the midpoint between the crests, called mid-valley. Measurements were focused on near-surface heights $(z)$, where shear overpowers buoyancy for neutrally stable ABL flows. Vertical coordinates are normalized with the ridge height $(H)$
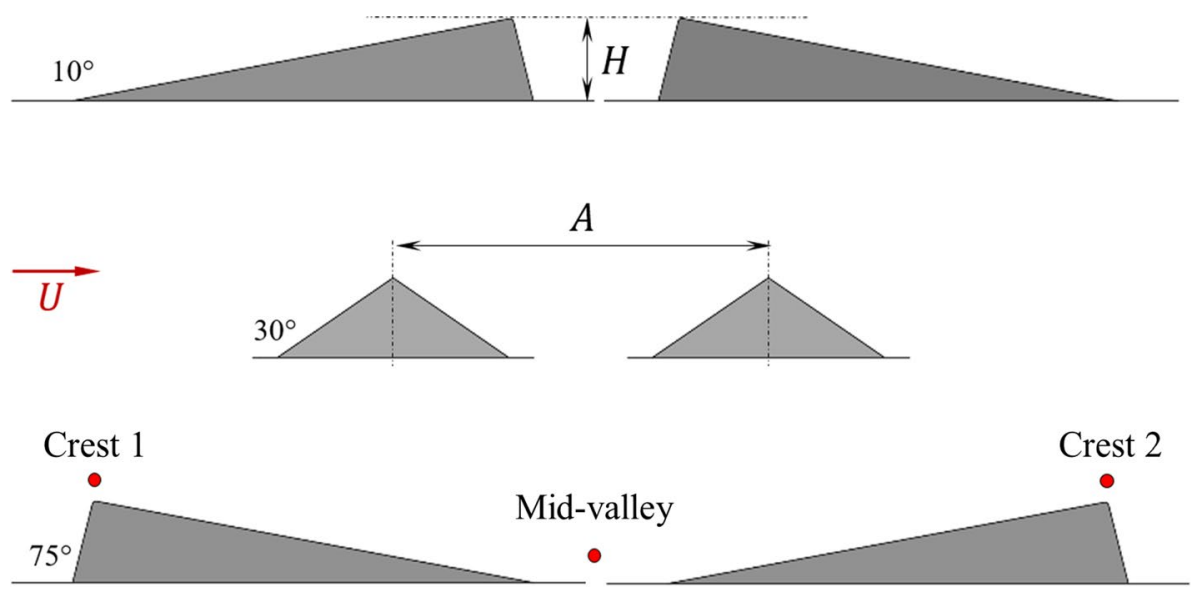

Fig. 1 Lateral view of the generic idealized valley geometries and analysis positions, where $U$ represents the inflow direction, $H$ the valley depth, $A$ the valley width, and the angles correspond to the inclinations of the windward slopes of the first ridges that form the valleys 
and are terrain following, i.e., expressed as heights above ground level, a.g.l. $(z / H)$. These are presented in Table 1, together with the absolute values $(z)$.

\section{Results}

Time-averaged turbulence properties analyzed here are turbulence intensities $(\bar{I}=\bar{\sigma} / \bar{u})$, velocity fluctuations $(\bar{\sigma})$, wind shear or vertical fluxes $\left(\overline{u^{\prime} w^{\prime}}\right)$, horizontal fluxes $\left(\overline{u^{\prime} v^{\prime}}\right)$, and longitudinal integral length scales of turbulence $\left(\bar{L}_{U}^{\bar{x}}\right)$. Furthermore, energy spectra $\left(f S / \sigma^{2}\right)$ provide an indication of the turbulent kinetic energy $(e)$ of the flows and depend on the spectral density of the normalized standard deviation of the one-dimensional velocity component and its reduced frequency, $f z / U$ (VDI 2000). The length scale quantifies the lengths of the energy-intensive eddies in the flows and are derived from the autocorrelation function, $R$ (Pope 2000; Foken 2008). For the present study, calculations of $R$ assume the validity of the hypothesis of frozen turbulence proposed by Taylor (1938). Mean flow parameters are normalized with the time-averaged reference speed $\left(U_{0}\right)$ and with the ridge height $(H)$ for $\overline{L_{U}^{x}}$. All time-averaged flow properties other than the covariances are represented without overbars in the subsequent analyses.

\subsection{Undisturbed Flow Characteristics}

Profiles of each of the components of turbulence intensity of the undisturbed flow above flat terrain, presented in Fig. 2, yield a moderately rough classed ABL flow that corresponds to flows over grass or farmlands (VDI 2000). Maximum observed values of each component are expectedly found at $z / H=0.15\left(I_{U} \approx 0.19, I_{V} \approx 0.16, I_{W} \approx 0.1\right)$. The ratios of longitudinal to lateral and longitudinal to vertical turbulence at $z / H=0.15$ are $I_{U}: I_{V}: I_{W} \approx 1: 0.8: 0.5$, which is in agreement with theoretical values, $I_{U}: I_{V}: I_{W} \approx 1$ : 0.75: 0.5 (VDI 2000). For a model scale of 1:1000, the corresponding full-scale aerodynamic surface roughness length $\left(z_{0}\right)$ is approximately $0.025 \pm 0.015 \mathrm{~m}$ and the profile exponent $(\alpha)$ is $0.14 \pm 0.01$. The semi-logarithmic relationship between $z_{0}$ and $\alpha$ also yields a moderately rough classed ABL flow.

Vertical profiles of the normalized shear $\left(\overline{u^{\prime} w^{\prime}} / U_{0}^{2}\right)$ in Fig. 3 are contained within $\mathrm{a} \pm 5 \%$ range centred on the near-surface values up to $z / H \approx 1.25$. This indicates that the full-scale depth of the atmospheric surface layer (ASL) is approximately $100 \mathrm{~m}$ for a

Table 1 Measurement heights above local terrain in dimensionless $(z / H)$ and absolute $(z)$ coordinates for a model scale of $1: 1000$

\begin{tabular}{ll}
\hline Dimensionless heights $z / H$ & $\begin{array}{l}\text { Absolute heights at } \\
\text { model scale 1:1000 } \\
z(\mathrm{~m})\end{array}$ \\
\hline 0.15 & 12 \\
0.25 & 20 \\
0.38 & 30 \\
0.63 & 50 \\
0.94 & 75 \\
1.25 & 100 \\
1.88 & 150 \\
2.5 & 200 \\
\hline
\end{tabular}



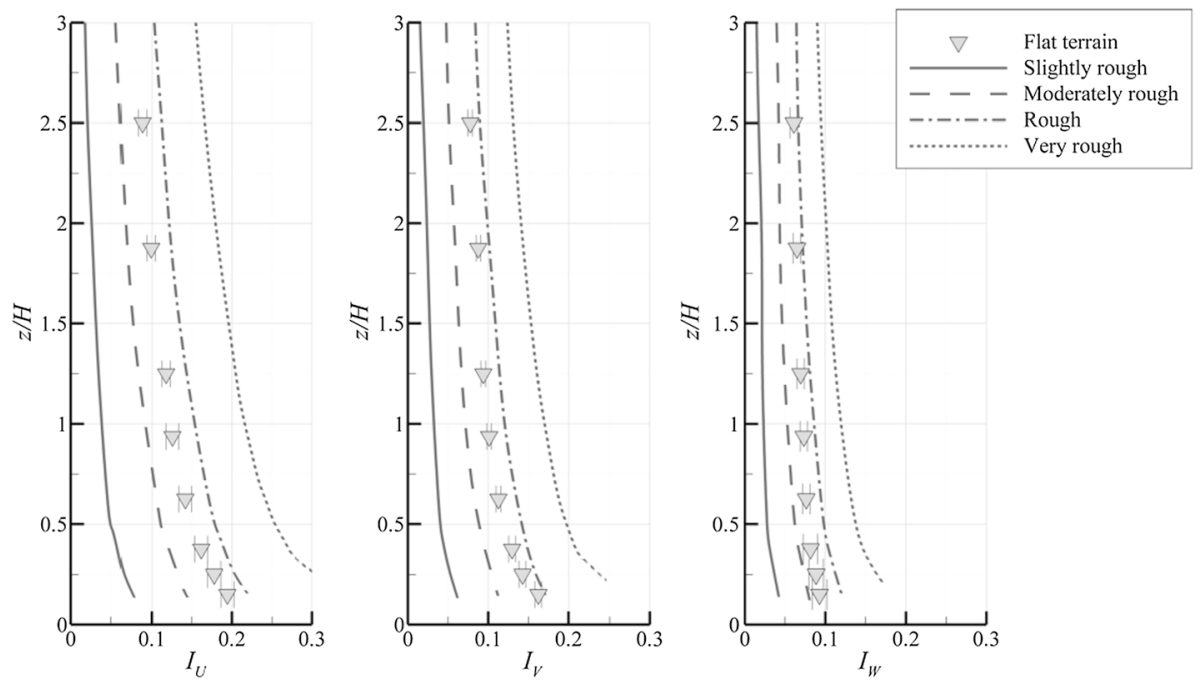

Fig. 2 Vertical profiles of longitudinal $\left(I_{U}\right)$, lateral $\left(I_{V}\right)$, and vertical $\left(I_{W}\right)$ turbulence intensity components above flat terrain. Curves represent the lower limits of the reference profiles of turbulence roughness classes (VDI 2000)
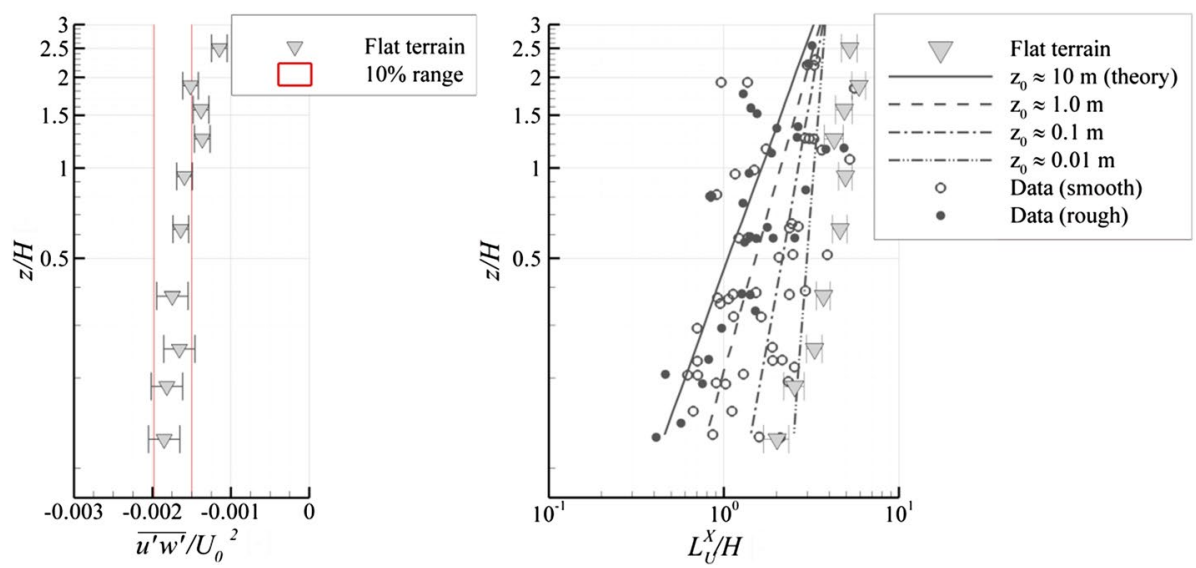

Fig. 3 Semi-logarithmic vertical profiles of the normalized mean vertical fluxes $\left(\overline{u^{\prime} w^{\prime}} / U_{0}^{2}\right)$ and logarithmic vertical profile of the normalized mean longitudinal integral length scales $\left(L_{U}^{X} / H\right)$ above flat terrain. Reference lines of $\overline{u^{\prime} w^{\prime}} / U_{0}^{2}$ represent the limits of a $10 \%$ range centred on the mean from the lowest $5 \mathrm{~cm}$ a.g.l. and those of $L_{U}^{X} / H$ represent functional relationships with reference values of $z_{0}$ (Counihan 1975)

model scale of 1:1000. The ASL roughly corresponds to the lowest $10 \%$ of the neutrally stable ABL, hence the modelled ABL has a depth of approximately $1000 \mathrm{~m}$ at fullscale (Stull 2000). The corresponding ratio between valley depth $(H)$ and ABL height is $\approx 0.08$. Profiles of the longitudinal integral length scales $\left(L_{U}^{X} / H\right)$ present the closest agreement with the functional relationship with $z_{0}$ at $z / H \leq 0.25$, where $L_{U}^{X} / H$ corresponds to values of $z_{0}$ of moderately rough classed ABL flows. At higher altitudes, values of $z_{0}$ shift to the slightly rough class. Considering the scatter of the reference data, 
we conclude that the profile of $L_{U}^{X} / H$ is physically consistent with a moderately-rough ABL flow above flat terrain.

Spectral distributions of the longitudinal $\left(f S_{U} / \sigma_{U}^{2}\right)$, lateral $\left(f S_{V} / \sigma_{U}^{2}\right)$, and vertical $\left(f S_{W} / \sigma_{U}^{2}\right)$ turbulent energy of the undisturbed flow at $z / H=0.15$ are displayed in Fig. 4. All components show good agreement with the reference data from the experiments of Kaimal et al. (1972) and Simiu and Scanlan (1986). The peak of the longitudinal component $\left(f S_{U} / \sigma_{U}^{2} \approx 0.2\right)$ is $\approx 18 \%$ larger than that of Kaimal et al. (1972) and $\approx 5 \%$ smaller than obtained by Simiu and Scanlan (1986). The corresponding reduced frequency $(f z / U \approx 0.08)$ is $\approx 60 \%$ larger than found by Kaimal et al. (1972) and $\approx 50 \%$ smaller than Simiu and Scanlan (1986). Peaks of the lateral $\left(f S_{V} / \sigma_{U}^{2} \approx 0.2\right)$ and vertical $\left(f S_{W} / \sigma_{U}^{2} \approx 0.3\right)$ spectra are $\approx 18 \%$ and $\approx 25 \%$ (respectively) larger than observed by Kaimal et al. (1972). These also occur at larger frequencies than those of Kaimal et al. (1972), with increases of $\approx 54 \%$ and $\approx 7 \%$ found for the frequencies of lateral $(f z / U \approx 0.28)$ and vertical $(f z / U \approx 0.3$ ) components, respectively. Within the inertial subranges of the respective distributions, the data exhibit an approximate $-2 / 3$ slope that is consistent with Kolmogorov theory.

\subsection{Flows Above Valleys}

\subsubsection{Crest 1}

Flows above the crests of the first ridges display slope-dependent increases of longitudinal velocity component $\left(U / U_{0}\right)$ over the undisturbed flow data, with the largest gains predictably occurring nearest to the surface. A maximum increase of $\approx 45 \%$ over the undisturbed flow is found for the $30^{\circ}$ geometry $\left(U / U_{0} \approx 0.8\right.$ at $\left.z / H=0.15\right)$ and is followed by those of the $10^{\circ}$ and $75^{\circ}$ geometries with increases of $\approx 40 \%$ and $\approx 25 \%$, respectively. The lateral velocity component $\left(V / U_{0}\right)$ is expectedly less affected by the presence of the first ridges, which is verified by the closest agreement with the undisturbed flow data of all velocity components; the value of $V / U_{0}$ is not equal to zero due to the lateral inhomogeneities mentioned in Sect. 2.1. The vertical velocity component $\left(W / U_{0}\right)$ exhibits increases relative to
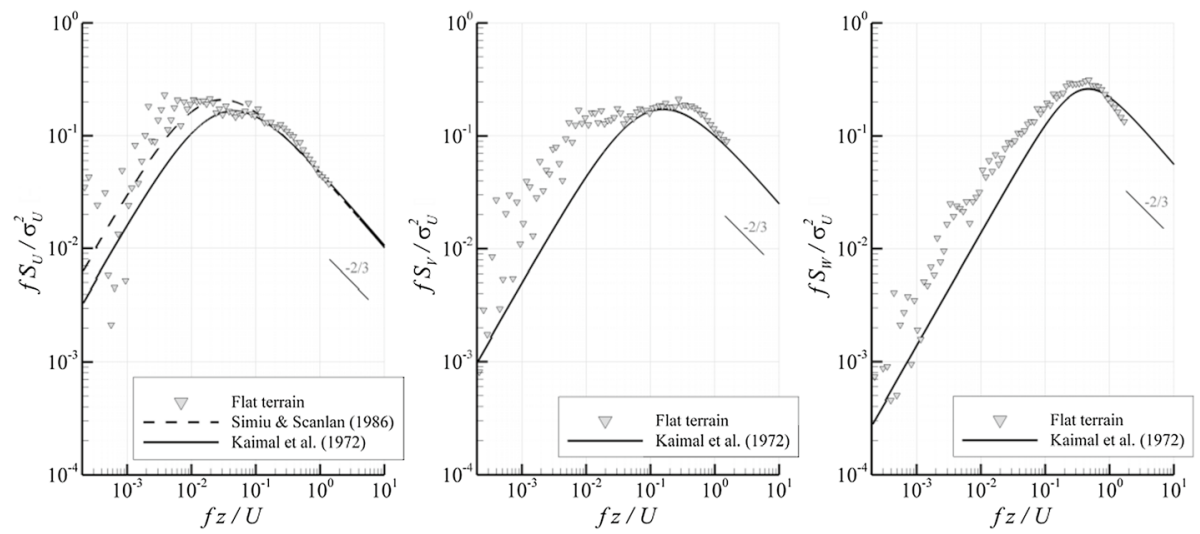

Fig. 4 Spectral distributions of the normalized longitudinal $\left(f S_{U} / \sigma_{U}^{2}\right)$, lateral $\left(f S_{V} / \sigma_{U}^{2}\right)$, and vertical $\left(f S_{W} / \sigma_{U}^{2}\right)$ turbulent energy as functions of reduced frequency $(f z / U)$ at $z / H=0.15$ above flat terrain. Reference curves represent the data from Kaimal et al. (1972) and Simiu and Scanlan (1986) and reference lines the $-2 / 3$ slopes of the inertial subranges according to Kolmogorov theory 
the undisturbed flow of over an order of magnitude for all geometries at $z / H<1$; values of $W / U_{0}$ predictably present inverse slope trends to $U / U_{0}$, with the maximum value of $W / U_{0}$ $(\approx 0.5$ at $z / H=0.15)$ found atop the $75^{\circ}$ slope, being $\approx 50 \%$ and $\approx 75 \%$ larger than the $30^{\circ}$ and $10^{\circ}$ counterparts, respectively.

Longitudinal velocity fluctuations $\left(\sigma_{U} / U_{0}\right)$, displayed in Fig. 5, show close agreement with the undisturbed flow data for all valley geometries at $z / H \geq 0.63$. Nearer to the surface, the $75^{\circ}$ geometry generates the largest observed increases of $\sigma_{U} / U_{0}$ above crest 1 . The maximum observed magnitude of $\sigma_{U} / U_{0}(\approx 0.12$ at $z / H=0.15)$ corresponds to an increase of $\approx 20 \%$ over the undisturbed flow. Inversely, the value of $\sigma_{U} / U_{0}$ unexpectedly decreases by $\approx 15 \%$ with regard to the undisturbed flow at $z / H=0.15$ atop the $10^{\circ}$ windward slope. Lateral components of the velocity fluctuations present the largest near-surface magnitudes of the fluctuations above crest 1 . The maximum observed magnitude $\left(\sigma_{V} / U_{0} \approx 0.2\right.$ at $\left.z / H=0.15\right)$ is found at atop the $75^{\circ}$ windward slope and is about twice that of the undisturbed flow and the $10^{\circ}$ geometry (and $\approx 54 \%$ larger than the maximum of the $30^{\circ}$ geometry). The maximum magnitude of the vertical velocity fluctuations $\left(\sigma_{W} / U_{0} \approx 0.1\right.$ at $\left.z / H=0.15\right)$ is found atop the $75^{\circ}$ slope and is approximately twice that of the undisturbed flow and the $10^{\circ}$ geometry (and $\approx 43 \%$ larger than the $30^{\circ}$ geometry). Ratios of longitudinal to lateral and longitudinal to vertical turbulence at $z / H=0.15$ are $\sigma_{U}: \sigma_{V}: \sigma_{W} \approx 1: 1.7: 0.9, \approx 1: 1.4: 0.8$, and $\approx 1: 1.1: 0.6$ for the $75^{\circ}, 30^{\circ}$, and $10^{\circ}$ geometries, respectively.

The constant shear properties that characterize ASL flows above flat terrain are lost due to the presence of the first ridges of each of the valleys. This is ascertained from the heightdependent variations of the vertical fluxes $\left(\overline{u^{\prime} w^{\prime}} / U_{0}^{2}\right)$, which are displayed in Fig. 6 . These exceed $\mathrm{a} \pm 5 \%$ range centred on the average of the corresponding near-surface values (from $z / H \leq 0.63$ ) for all valley geometries. The largest deviations of $\overline{u^{\prime} w^{\prime}} / U_{0}^{2}$ relative to the undisturbed flow occur atop the $75^{\circ}$ windward slope, the maximum observed magnitude $\left(\left|\overline{u^{\prime} w^{\prime}} / U_{0}^{2}\right| \approx 0.006\right.$ at $\left.z / H=0.25\right)$ corresponding to an approximate threefold increase over the maxima of the other geometries and the undisturbed flow data. Horizontal fluxes $\left(\overline{u^{\prime} v^{\prime}} / U_{0}^{2}\right)$ and integral length scales $\left(L_{U}^{X} / H\right)$, also presented in Fig. 6, are the least affected of the time-averaged turbulence parameters above crest 1 . Both properties exhibit the closest observed agreement with the data from the flow over flat terrain at all heights of the
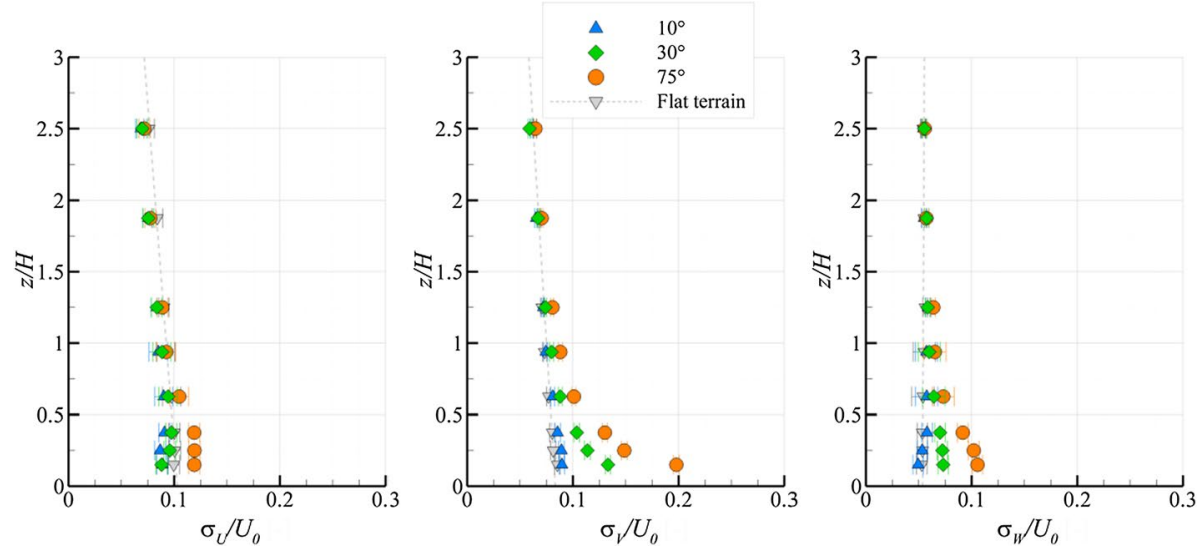

Fig. 5 Vertical profiles of the normalized mean longitudinal $\left(\sigma_{U} / U_{0}\right)$, lateral $\left(\sigma_{V} / U_{0}\right)$, and vertical $\left(\sigma_{W} / U_{0}\right)$ velocity fluctuation components above crest 1 

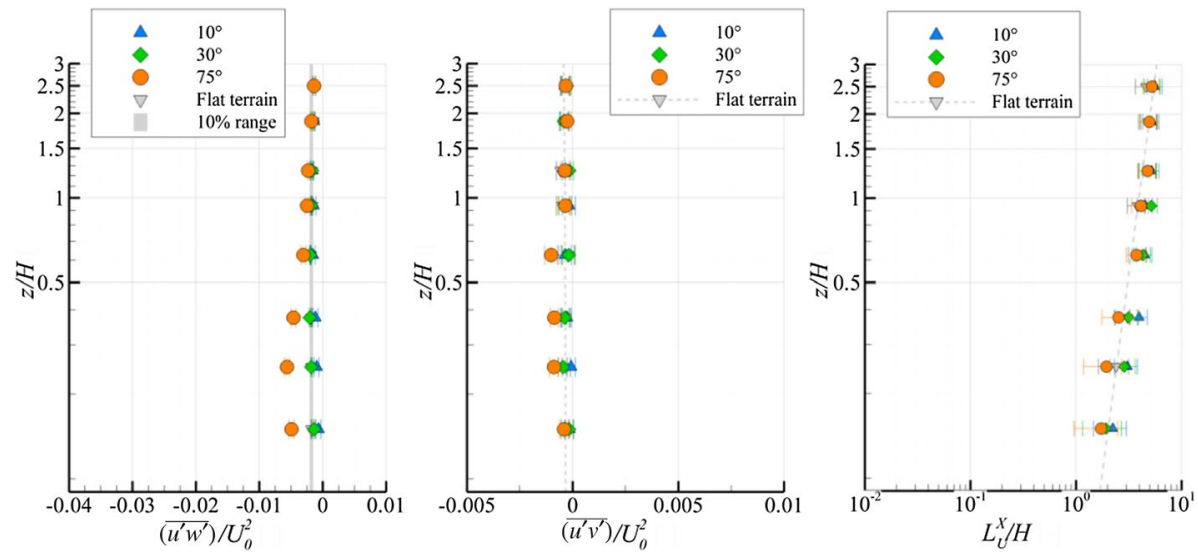

Fig. 6 Semi-logarithmic vertical profiles of the normalized mean vertical fluxes $\left(\overline{u^{\prime} w^{\prime}} / U_{0}^{2}\right)$, horizontal fluxes $\left(\overline{u^{\prime} v^{\prime}} / U_{0}^{2}\right)$, and logarithmic vertical profiles of the normalized mean longitudinal integral length scales $\left(L_{U}^{X} / H\right)$ above crest 1

respective vertical profiles. The negligible scatter between data from the different slopes, which is verified by the data contained within the corresponding ranges of uncertainty in the plots, indicates that both of these properties do not depend on the slopes.

The peak energy of the horizontal components of the spectra, $f S_{U} / \sigma_{U}^{2}$ and $f S_{V} / \sigma_{U}^{2}$, at $z / H=0.15$ (displayed in Fig. 7) is predictably larger than the undisturbed flow for all valley geometries. Maximum increases of $\approx 10 \%$ relative to the peaks of the undisturbed flow are observed for both components atop the $30^{\circ}$ and $75^{\circ}$ windward slopes $\left(f S_{U} / \sigma_{U}^{2} \approx 0.22\right.$ and $f S_{V} / \sigma_{U}^{2} \approx 0.23$ ). Distributions of $f S_{W} / \sigma_{U}^{2}$ act inversely, with decreases of peak energy compared to the flat terrain being found for the $30^{\circ}$ and $75^{\circ}$ slopes. The largest of the observed decreases, of $\approx 30 \%$, is found atop the $30^{\circ}$ slope (where $f S_{W} / \sigma_{U}^{2} \approx 0.21$ ).
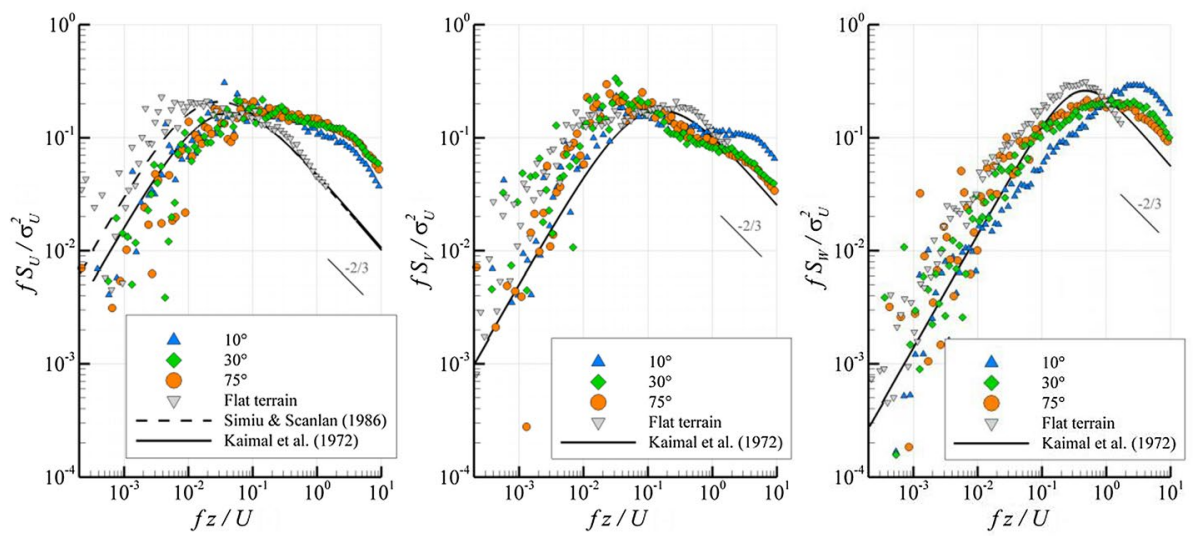

Fig. 7 Spectral distributions of the normalized longitudinal $\left(f S_{U} / \sigma_{U}^{2}\right)$, lateral $\left(f S_{V} / \sigma_{U}^{2}\right)$, and vertical $\left(f S_{W} / \sigma_{U}^{2}\right)$ turbulent energy as function of reduced frequency $(f z / U)$ at $z / H=0.15$ above crest 1 . Reference curves represent the data from Kaimal et al. (1972) and Simiu and Scanlan (1986) and reference lines the $-2 / 3$ slopes of the inertial subranges according to Kolmogorov theory 
Peaks of $f S_{U} / \sigma_{U}^{2}$ and $f S_{W} / \sigma_{U}^{2}$ occur at higher frequencies than those of the undisturbed flow. Maximum increases of roughly fourfold and twofold are found atop the $30^{\circ}$ slope for $f S_{U} / \sigma_{U}^{2}(f z / U \approx 0.3)$ and $f S_{W} / \sigma_{U}^{2}(f z / U \approx 1.2)$, respectively. Peaks of $f S_{V} / \sigma_{U}^{2}$ occur at lower frequencies than the undisturbed flow, the largest decrease of $\approx 60 \%$ being found for the peak of the $75^{\circ}$ slope $(f z / U \approx 0.08)$. With the exception of $f S_{W} / \sigma_{U}^{2}$, the shifts of frequency relative to the undisturbed flow are independent of slope inclinations. The peak of $f S_{W} / \sigma_{U}^{2}$ of the $10^{\circ}$ geometry occurs at a frequency $(f z / U \approx 2.9)$ that is $\approx 70 \%$ larger than the other valleys. At the lower frequencies of the respective inertial subranges, $f S_{U} / \sigma_{U}^{2}$ and $f S_{V} / \sigma_{U}^{2}$ exhibit shallower slopes than proposed by Kolmogorov theory.

\subsubsection{Mid-valley}

Flow separation originates at crest 1 and generates steady recirculation zones inside the valleys, as highlighted by the longitudinal flow reversal $\left(U / U_{0}<0\right)$ at $z / H<1$ above the midvalley (in Fig. 8). The recirculation zones extend to roughly half of the valley for all geometries. The largest observed magnitude of reversed flow $\left(U / U_{0} \approx-0.16\right.$ at $\left.z / H=0.15\right)$ is found for the $30^{\circ}$ geometry and is $\approx 71 \%$ smaller (in magnitude) than the undisturbed flow data at the same height. This is $\approx 60 \%$ larger than $U / U_{0}$ of the $75^{\circ}$ geometry, which indicates that the leeside slopes also affect flows downwind from the first ridges. The lateral component $\left(V / U_{0}\right)$ increases over the undisturbed flow at $z / H<1$ for all valley geometries, which indicates the occurrence of lateral flow acceleration in the channels between ridges. Maximum magnitudes of $V / U_{0}(\approx 0.06)$ are found for $75^{\circ}$ (at $z / H=0.15$ ) and $30^{\circ}$ geometries $(z / H=0.38)$ and are $\approx 50 \%$ larger than that of the $10^{\circ}$ geometry (found at $z / H=0.15)$. Downward flows $\left(W / U_{0}<0\right)$ extending to $z / H>2.5$ characterize the aforementioned vertical plane recirculation zones. The maximum magnitude of downward flow $\left(W / U_{0} \approx-0.06\right)$ is found at $z / H=0.94$ above the $10^{\circ}$ geometry and is roughly twice the maxima of $\left|W / U_{0}\right|$ of $75^{\circ}$ and $30^{\circ}$ geometries (both at $z / H=1.25$ ).

Maximum magnitudes of all components of the velocity fluctuations above the midvalley (presented in Fig. 9) are found near ridge height $(z / H \approx 1)$ for the $75^{\circ}$ geometry. The maximum of the longitudinal components $\left(\sigma_{U} / U_{0} \approx 0.26\right.$ at $\left.z / H=1.25\right)$ is over twice that of the undisturbed flow. Moreover, this constitutes increases of $\approx 8 \%$ and $\approx 30 \%$
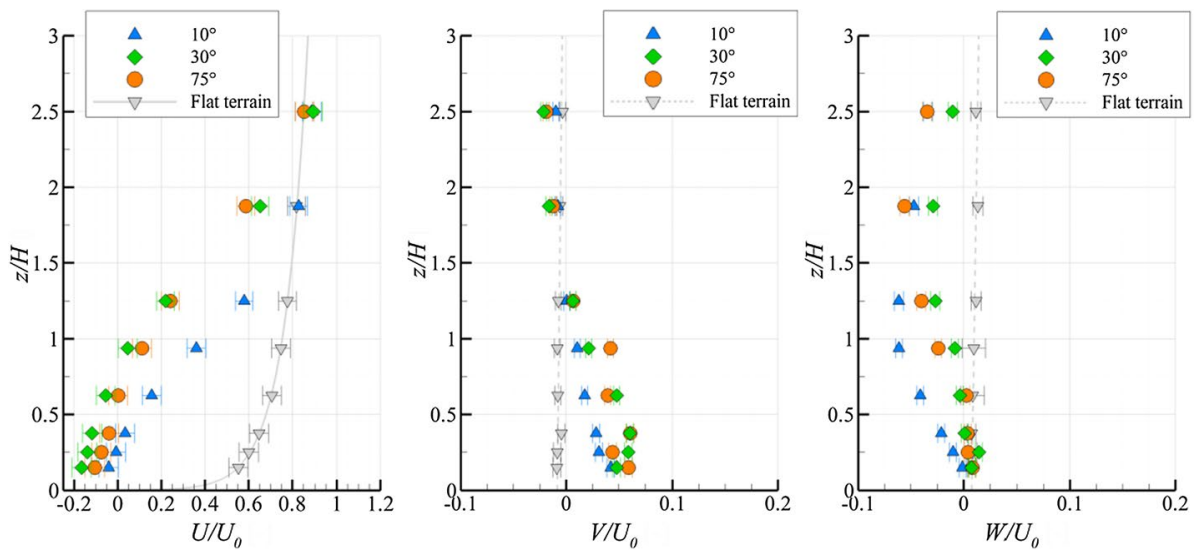

Fig. 8 Vertical profiles of the normalized mean longitudinal $\left(U / U_{0}\right)$, lateral $\left(V / U_{0}\right)$, and vertical $\left(W / U_{0}\right)$ velocity components above the mid-valley 

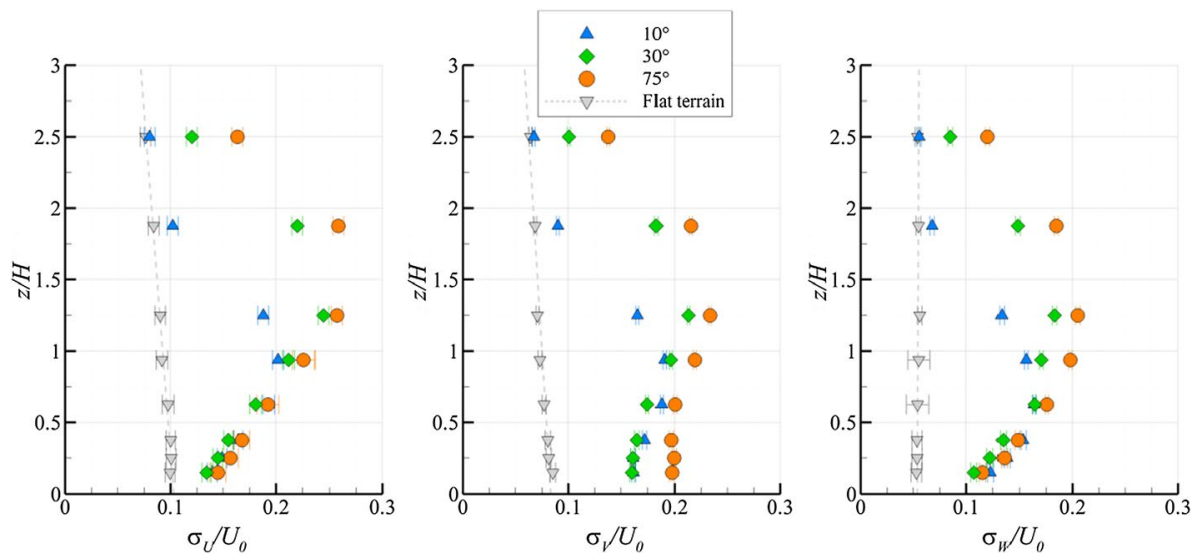

Fig. 9 Vertical profiles of the normalized mean longitudinal $\left(\sigma_{U} / U_{0}\right)$, lateral $\left(\sigma_{V} / U_{0}\right)$, and vertical $\left(\sigma_{W} / U_{0}\right)$ velocity fluctuation components above the mid-valley

over the maxima of the $30^{\circ}$ (observed at $z / H=1.25$ ) and $10^{\circ}$ (at $z / H=0.94$ ) geometries, respectively. For all geometries, the maximum magnitudes of $\sigma_{V} / U_{0}$ and $\sigma_{W} / U_{0}$ are found at equivalent heights to the maxima of $\sigma_{U} / U_{0}$. The largest magnitude of the lateral fluctuations $\left(\sigma_{V} / U_{0} \approx 0.26\right)$ is found at $z / H=1.25$ above the $75^{\circ}$ geometry and is $\approx 14 \%$ and $\approx 26 \%$ larger than the maxima of the $30^{\circ}$ (at $z / H=1.25$ ) and $10^{\circ}$ (at $z / H=0.94)$ geometries, respectively. The maximum magnitude of the vertical components $\left(\sigma_{W} / U_{0} \approx 0.2\right.$ at $\left.z / H=1.25\right)$ is observed for the $75^{\circ}$ geometry and is $\approx 11 \%$ and $\approx 54 \%$ larger than the maxima of the $30^{\circ}$ (at $z / H=1.25$ ) and $10^{\circ}$ (at $z / H=0.94$ ) geometries, respectively. Nearer to the surfaces (at $z / H<0.63$ ), $\sigma_{V} / U_{0}$ exceeds $\sigma_{U} / U_{0}$ for all geometries. This is highlighted by the ratios of longitudinal to lateral and longitudinal to vertical turbulence at $z / H=0.15$, with $\sigma_{U}: \sigma_{V}: \sigma_{W} \approx 1: 1.3: 0.7, \approx 1: 1.2: 0.9$, and $\approx 1: 1.1: 0.9$ for the $75^{\circ}, 30^{\circ}$, and $10^{\circ}$ geometries, respectively.

The largest intensities of $\overline{u^{\prime} w^{\prime}} / U_{0}^{2}$, presented in Fig. 10, coincide with the heights of maximum $\sigma_{U} / U_{0}$ and $\sigma_{W} / U_{0}$ values for all geometries $(z / H \approx 1)$. The maximum $\left|\overline{u^{\prime} w^{\prime}} / U_{0}^{2}\right|$ $(\approx 0.03)$ is found for the $75^{\circ}$ geometry at $z / H=1.25$ and is over an order of magnitude larger than that of the undisturbed flow. This also constitutes increases of $\approx 24 \%$ and $\approx 63 \%$ relative to the maxima of $30^{\circ}$ (found at $z / H=1.25$ ) and $10^{\circ}$ (at $z / H=0.94$ ) geometries, respectively. Effects of the valleys on $\overline{u^{\prime} v^{\prime}} / U_{0}^{2}$ are the least conspicuous of all mean turbulence properties above the mid-valley and the largest magnitudes are found at different heights to those of $\sigma_{U} / U_{0}$ and $\sigma_{V} / U_{0}$. The maximum observed magnitude $\left(\left|\overline{u^{\prime} v^{\prime}} / U_{0}^{2}\right| \approx 0.002\right)$ is found at $z / H=0.94$ for the $75^{\circ}$ valley and is $\approx 14 \%$ and $\approx 32 \%$ larger than the maxima of $30^{\circ}$ (at $z / H=0.63$ ) and $10^{\circ}$ (at $z / H=0.38$ ) geometries, respectively. At $z / H<1$, values of $L_{U}^{X} / H$ decrease by at least an order of magnitude with regard to the flow over flat terrain. The largest observed decrease of roughly two orders of magnitude from the undisturbed flow data is found for the $75^{\circ}$ geometry $\left(L_{U}^{X} / H \approx 0.04\right.$ at $z / H=0.63)$. The smallest energy-intensive eddies of the $10^{\circ}(z / H=0.25)$ and $30^{\circ}$ $(z / H=0.63)$ geometries correspond to twofold and fivefold increases over that of the $75^{\circ}$ valley. At $z / H>1$, the flows are driven by larger eddies that tend to converge with the eddy sizes of the undisturbed flow with increasing altitudes. 

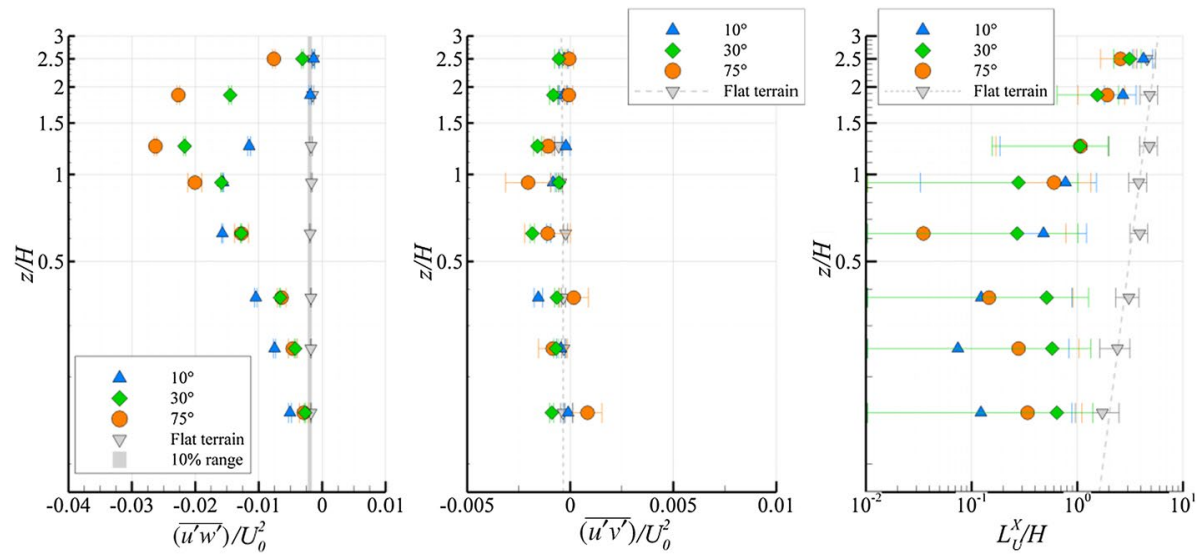

Fig. 10 Semi-logarithmic vertical profiles of the normalized mean vertical shear $\left(\overline{u^{\prime} w^{\prime}} / U_{0}^{2}\right)$, horizontal fluxes $\left(\overline{u^{\prime} v^{\prime}} / U_{0}^{2}\right)$, and logarithmic vertical profiles of the normalized mean longitudinal integral length scales $\left(L_{U}^{X} / H\right)$ above the mid-valley
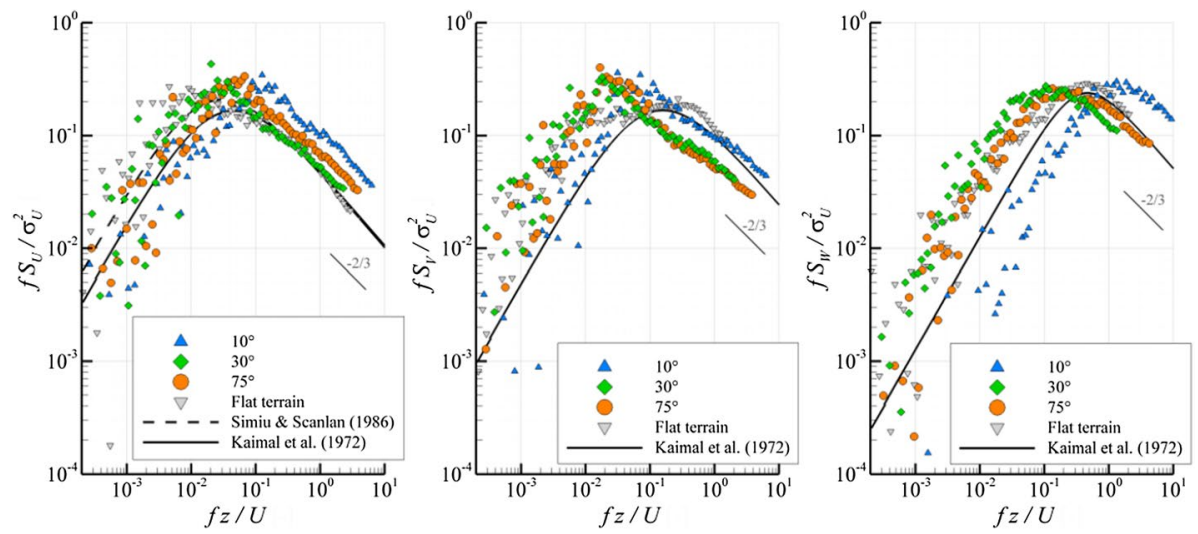

Fig. 11 Spectral distributions of the normalized longitudinal $\left(f S_{U} / \sigma_{U}^{2}\right)$, lateral $\left(f S_{V} / \sigma_{U}^{2}\right)$, and vertical $\left(f S_{W} / \sigma_{U}^{2}\right)$ turbulent energy as function of reduced frequency $(f z / U)$ at $z / H=0.15$ above the mid-valley. Reference curves represent the data from Kaimal et al. (1972) and Simiu and Scanlan (1986) and reference lines the $-2 / 3$ slopes of the inertial subranges according to Kolmogorov theory

Distributions of all components of the spectra are presented in Fig. 11. The maximum longitudinal peak energy, $f S_{U} / \sigma_{U}^{2} \approx 0.4$, is found for the $10^{\circ}$ geometry and is $\approx 9 \%, \approx 21 \%$, and $\approx 50 \%$ larger than the peaks of the $75^{\circ}, 30^{\circ}$, and flat terrain cases, respectively. Peaks of $f S_{U} / \sigma_{U}^{2}$ occur at larger frequencies than the undisturbed flow, the largest of which corresponds to an increase of $\approx 63 \%$ for the $10^{\circ}$ geometry $(f z / U \approx 0.13)$. The maximum peak of $f S_{V} / \sigma_{U}^{2}(\approx 0.4)$ is found for the $75^{\circ}$ valley and corresponds to increases of $\approx 16 \%$ and $\approx 37 \%$ over those of the $30^{\circ}$ and $10^{\circ}$ geometries (respectively) and twice that of the undisturbed flow. These occur at lower frequencies than that of the undisturbed flow. Those of the $30^{\circ}(f z / U \approx 0.019)$ and $75^{\circ}(f z / U \approx 0.016)$ geometries constitute decreases of about an order of magnitude relative to the flat terrain case. Furthermore, the inertial subranges of $f S_{V} / \sigma_{U}^{2}$ have shallower slopes than predicted by Kolmogorov theory. As indicated by the similar distributions to the undisturbed flow, vertical components are the least affected of 
the spectra. The maximum peak $\left(f S_{W} / \sigma_{U}^{2} \approx 0.3\right.$ ) is observed for the $10^{\circ}$ geometry and is comparable to that of the undisturbed flow and larger than the peaks of the $75^{\circ}(\approx 7 \%)$ and $30^{\circ}(\approx 16 \%)$ geometries. The peak of the $10^{\circ}$ valley occurs at a frequency $(f z / U \approx 1.2)$ over twice that of the undisturbed flow, whereas those of the $75^{\circ}$ and $30^{\circ}$ geometries constitute decreases of $\approx 70 \%$ and $\approx 76 \%$, respectively.

\subsubsection{Crest 2}

Near-surface increases of $U / U_{0}$ (displayed in Fig. 12) relative to the undisturbed flow only occur above crest 2 of the $10^{\circ}$ valley. The largest observed increase $(\approx 25 \%)$ is found at $z / H=0.15$, where $U / U_{0} \approx 0.7$. The other geometries decrease relative to the flow over flat terrain, the largest of which for the $30^{\circ}$ geometry $(\approx 25 \%$ decrease at $z / H=0.63)$. The lateral component $\left(V / U_{0}\right)$ is only influenced by the valleys at $z / H \leq 0.63$ and is in agreement with the undisturbed flow at higher altitudes. The largest observed magnitude $\left(V / U_{0} \approx 0.11\right)$ is found at $z / H=0.15$ for the $30^{\circ}$ valley and is about four times larger than the data from the other valleys. Similar to the findings made above crest 1 , the vertical component $\left(W / U_{0}\right)$ has an inverse slope trend to $U / U_{0}$ above crest 2 . The maximum magnitude of $W / U_{0}$ is found for the $10^{\circ}$ geometry $\left(W / U_{0} \approx 0.3\right.$ at $\left.z / H=0.15\right)$ and is over two and five times larger than the maxima of the $30^{\circ}$ and $75^{\circ}$ geometries (respectively), which are found at the same height. The $10^{\circ}$ geometry has the steepest windward slope of the second ridge $\left(75^{\circ}\right)$, thus $W / U_{0}$ is the most affected of the velocity components due to the inclinations of the windward slopes of the second ridges.

The maximal magnitudes of $\sigma_{U} / U_{0}$ above crest 2 (presented in Fig. 13) are found at $z / H \approx 1$, the largest of which is observed for the $30^{\circ}$ geometry $\left(\sigma_{U} / U_{0} \approx 0.22\right.$ at $z / H=1.25$ ) and is approximately twice the maximum of the undisturbed flow (found at $z / H=0.15$ ). This corresponds to increases of $\approx 10 \%$ and $\approx 38 \%$ over the maxima of the $75^{\circ}$ (at $z / H=1.25$ ) and $10^{\circ}$ (at $z / H=0.94$ ) geometries, respectively. At $z / H \leq 0.38$, the largest magnitudes of $\sigma_{U} / U_{0}$ are those of the $75^{\circ}$ geometry, with the maximum found at $z / H=0.38\left(\sigma_{U} / U_{0} \approx 0.19\right)$. The maximum observed magnitudes of the lateral components $\left(\sigma_{V} / U_{0}\right)$ of all valley geometries are found at $z / H=0.15$ and constitute increases of at least threefold over the maximum of the undisturbed flow. The largest magnitude
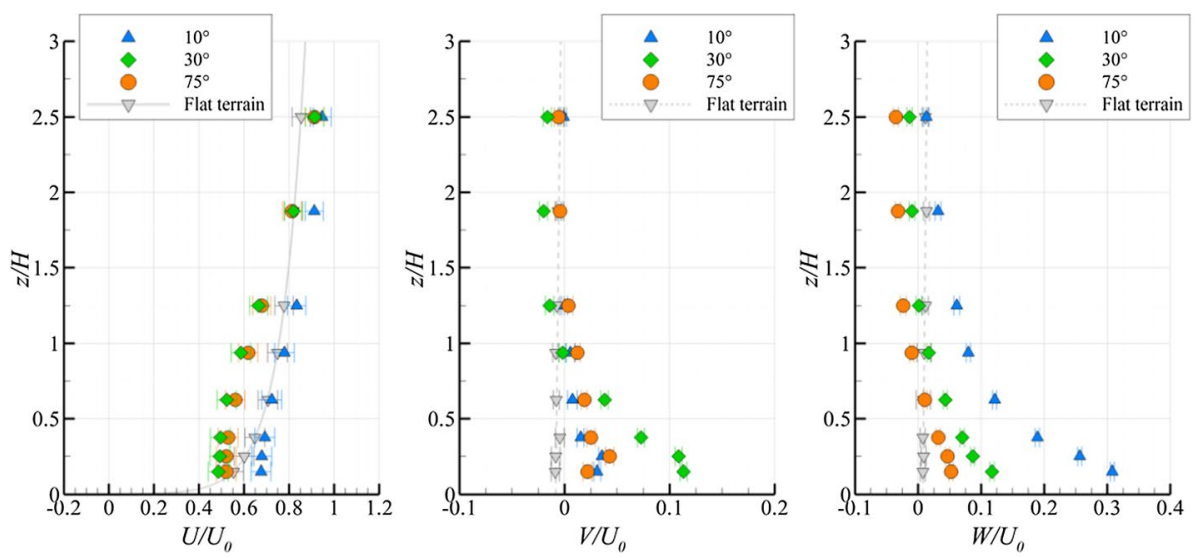

Fig. 12 Vertical profiles of the normalized mean longitudinal $\left(U / U_{0}\right)$, lateral $\left(V / U_{0}\right)$, and vertical $\left(W / U_{0}\right)$ velocity components above crest 2 

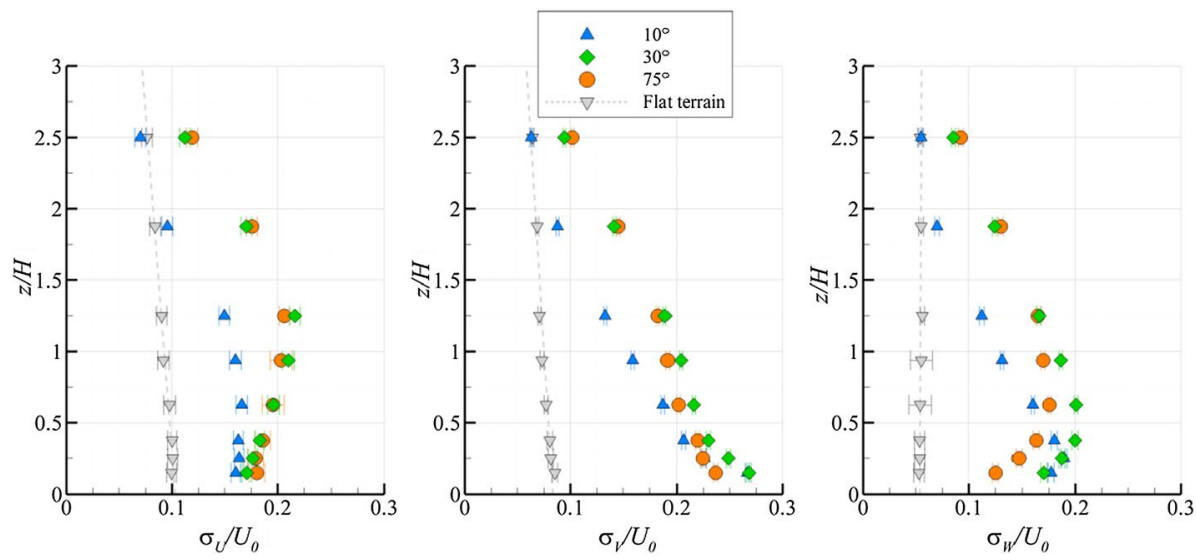

Fig. 13 Vertical profiles of the normalized mean longitudinal $\left(\sigma_{U} / U_{0}\right)$, lateral $\left(\sigma_{V} / U_{0}\right)$, and vertical $\left(\sigma_{W} / U_{0}\right)$ velocity fluctuation components above crest 2

$\left(\sigma_{V} / U_{0} \approx 0.27\right)$ is found for the $30^{\circ}$ geometry and is $\approx 5 \%$ and $\approx 13 \%$ larger than the maxima of the $10^{\circ}$ and $75^{\circ}$ valleys, respectively. The maximum magnitude of the vertical fluctuations is also observed for the $30^{\circ}$ geometry $\left(\sigma_{W} / U_{0} \approx 0.2\right.$ at $\left.z / H=0.63\right)$ and is four times larger than the maximum of the undisturbed flow $(z / H=0.15)$, which corresponds to increases of $\approx 5 \%$ and $\approx 18 \%$ over the maxima of the $10^{\circ}$ (found at $z / H=0.38$ ) and $75^{\circ}$ (at $z / H=0.63$ ) valleys, respectively. Ratios of longitudinal to lateral and longitudinal to vertical turbulence at $z / H=0.15$ are $\sigma_{U}: \sigma_{V}: \sigma_{W} \approx 1: 1.3: 0.7, \approx 1: 1.6: 1$, and $\approx 1: 1.7$ : 0.9 for the $75^{\circ}, 30^{\circ}$, and $10^{\circ}$ geometries, respectively.

Following the same slope trends observed for the velocity fluctuations, the maximum absolute value of $\overline{u^{\prime} w^{\prime}} / U_{0}^{2}$ above crest 2 (displayed in Fig. 14) is found above the $30^{\circ}$ valley $\left(\left|\overline{u^{\prime} w^{\prime}} / U_{0}^{2}\right| \approx 0.02\right.$ at $\left.z / H=0.94\right)$ and is about an order of magnitude larger than the maximum of the flow over flat terrain. This also corresponds to increases of $\approx 12 \%$ and $\approx 36 \%$ over the maxima of the $10^{\circ}$ (which is found at $z / H=0.25$ ) and $75^{\circ}$ (at
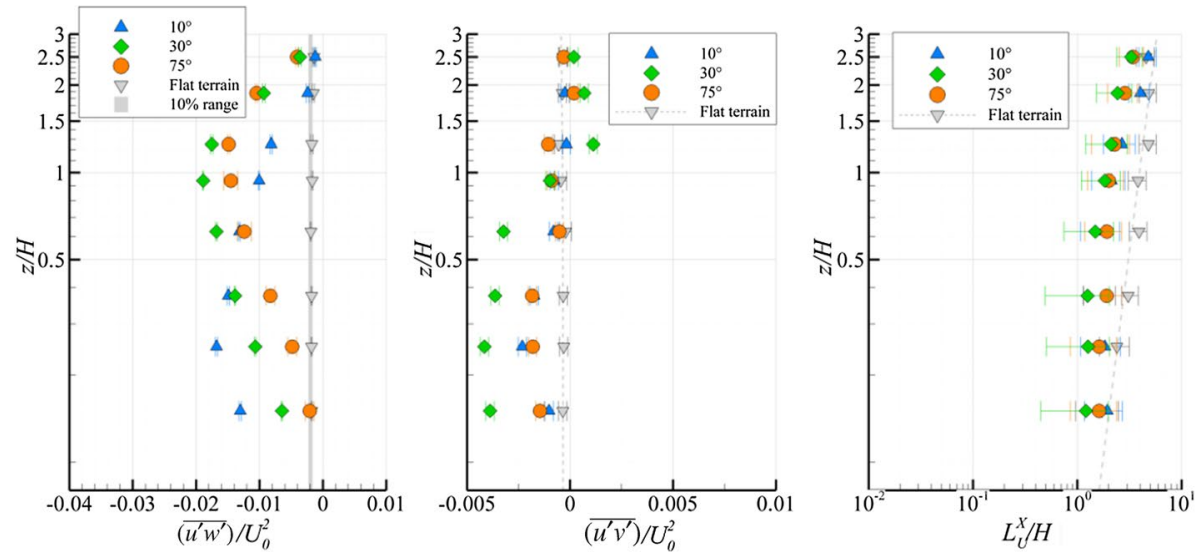

Fig. 14 Semi-logarithmic vertical profiles of the normalized mean vertical shear $\left(\overline{u^{\prime} w^{\prime}} / U_{0}^{2}\right)$, horizontal fluxes $\left(\overline{u^{\prime} v^{\prime}} / U_{0}^{2}\right)$, and logarithmic vertical profiles of the normalized mean longitudinal integral length scales $\left(L_{U}^{X} / H\right)$ above crest 2 
$z / H=0.94)$ valley geometries, respectively. These slope dependencies are also replicated by the horizontal fluxes above crest 2 , the maximum observed magnitude of $\overline{u^{\prime} v^{\prime}} / U_{0}^{2}$ being found for the $30^{\circ}$ geometry $\left(\left|\overline{u^{\prime} v^{\prime}} / U_{0}^{2}\right| \approx 0.004\right.$ at $\left.z / H=0.25\right)$. The maxima of $\overline{u^{\prime} v^{\prime}} / U_{0}^{2}$ of the $10^{\circ}$ and $75^{\circ}$ geometries, which are observed at the same altitude, are approximately half the magnitude of the maximum of the $30^{\circ}$ geometry. Profiles of $L_{U}^{X} / H$ are the least affected of the time-averaged turbulence properties above crest 2 . This is demonstrated by the closest observed agreement with the vertical profile of the undisturbed flow, with data from all geometries generally contained within the respective ranges of data uncertainty. This indicates that the most energy-intensive longitudinal eddies of the flows above crest 2 of each of the valley geometries have equivalent average lengths to those of the flow above flat terrain.

The maximum peak of longitudinal spectra (in Fig. 15) is observed for the $75^{\circ}$ geometry $\left(f S_{U} / \sigma_{U}^{2} \approx 0.32\right)$ and is $\approx 60 \%$ larger than that of the undisturbed flow. Peaks of the $30^{\circ}$ and $10^{\circ}$ geometries are $\approx 6 \%$ and $\approx 28 \%$ smaller, respectively. Frequencies of peak $f S_{U} / \sigma_{U}^{2}$ for $75^{\circ}$ and $30^{\circ}$ geometries $(f z / U \approx 0.16)$ are twice that of the undisturbed flow, whereas that of the $10^{\circ}$ valley occurs at an equivalent frequency. The largest peak of the lateral components $\left(f S_{V} / \sigma_{U}^{2} \approx 0.33\right.$ ) is found for the $30^{\circ}$ geometry and constitutes an increase of $\approx 65 \%$ over the undisturbed flow. Peaks of the $10^{\circ}$ and $75^{\circ}$ geometries are $\approx 3 \%$ and $\approx 12 \%$ smaller, respectively. Peaks of $f S_{V} / \sigma_{U}^{2}$ occur at lower frequencies than that of the undisturbed flow for all geometries. The largest decrease, $\approx 61 \%$, is found for the $10^{\circ}$ valley $(f z / U \approx 0.11)$ followed by the $30^{\circ}(\approx 54 \%)$ and $75^{\circ}(\approx 46 \%)$ geometries. At the lower frequencies of the inertial subranges $(f z / U<0.5)$, distributions of $f S_{V} / \sigma_{U}^{2}$ exhibit steeper slopes than proposed by Kolmogorov theory. The largest peak of $f S_{W} / \sigma_{U}^{2}(\approx 0.29)$ is found for the $10^{\circ}$ valley and is $\approx 3 \%$ smaller than the flat terrain case, those of the $30^{\circ}$ and $75^{\circ}$ geometries correspond to decreases of $\approx 10 \%$ and $\approx 17 \%$, respectively. Frequencies of peak $f S_{W} / \sigma_{U}^{2}$ are $\approx 61 \%$ and $\approx 71 \%$ smaller than that of the undisturbed flow for $30^{\circ}(f z / U \approx 0.19)$ and $10^{\circ}(f z / U \approx 0.14)$ geometries, respectively. Inversely, the frequency of the peak of the $75^{\circ}$ valley $(f z / U \approx 0.82$ ) is $\approx 61 \%$ larger than the flat terrain.
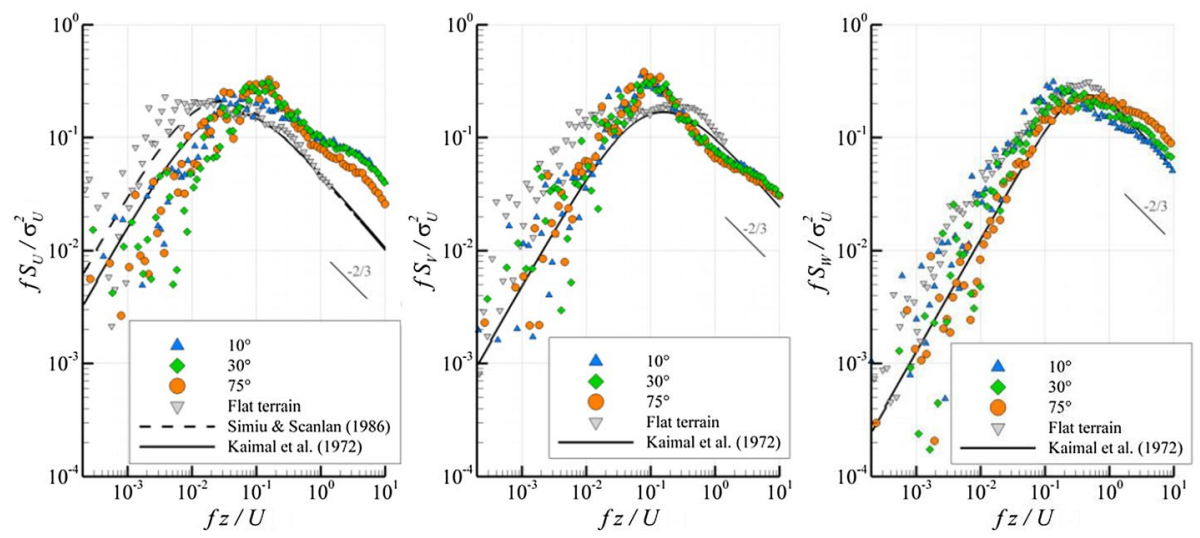

Fig. 15 Spectral distributions of the normalized longitudinal $\left(f S_{U} / \sigma_{U}^{2}\right)$, lateral $\left(f S_{V} / \sigma_{U}^{2}\right)$, and vertical $\left(f S_{W} / \sigma_{U}^{2}\right)$ turbulent energy as function of reduced frequency $(f z / U)$ at $z / H=0.15$ above crest 2 . Reference curves represent the data from Kaimal et al. (1972) and Simiu and Scanlan (1986) and reference lines the $-2 / 3$ slopes of the inertial subranges according to Kolmogorov theory 


\section{Discussion}

Above the crests of the first ridges (crest 1), increases in the longitudinal velocity component relative to the undisturbed flow mirror speed-up characteristics previously reported for flows above single hills with comparable windward slopes (e.g., Ayotte and Hughes 2004; Cao and Tamura 2007; Lubitz and White 2007). Maximum speed-ups are found for the smaller inclinations (the maximum atop the $30^{\circ}$ slope) and tend to decrease with increases of slope steepness. Turbulence characteristics are the least pronounced above crest 1 and generally exhibit inverse slope dependencies to the velocities. This is exemplified by the near-surface longitudinal velocity fluctuations, which exhibit decreasing magnitudes with decreasing slopes. In particular, these unexpectedly present smaller magnitudes than the undisturbed flow atop the $10^{\circ}$ slope. This may be attributed to dampening of longitudinal turbulence due to the gentle slope and its extended length rather than flow laminarization due to rapid flow distortion, as proposed by Cao and Tamura (2007). Results also indicate that near-surface transfers of turbulent energy from longitudinal to lateral and vertical directions take place above crest 1 and tend to increase with increasing slope steepness.

As highlighted by the longitudinal flow reversal observed above the mid-valley locations, vertical-plane recirculation zones originate above the first ridges of all geometries. This includes the $10^{\circ}$ geometry, for which flow separation was not reported in past studies of flows over symmetric hills of similar slopes (e.g., Cao et al. 2012). The nonsymmetric $10^{\circ}$ geometry has a steep leeside slope $\left(75^{\circ}\right)$ of the first ridge, which shows that vertical-plane flow separation is also driven by the leeside slopes. The lengths of recirculation zones are independent of the slopes and extend to roughly half the valley width, showing agreement with the average length observed at Perdigão (Menke et al. 2019). Flow dynamics within the recirculation zones are dominated by lateral turbulence that overpowers the longitudinal counterparts at the lowest measurement heights. This results from horizontal-plane flow separation around the side slopes of the first ridges and consequent lateral flow channelling in the spaces between ridges. The largest differences to the undisturbed flow data above the mid-valley are generally observed for the $75^{\circ}$ geometry, which indicates the dominance of the windward slopes of the first ridges. Based on these findings, increases in steepness of the windward slopes of the first ridges lead to increases of the three-dimensional turbulence characteristics above the inner valley regions.

Downstream from the vertical-plane recirculation zones the more turbulent nature of the near-surface flows is translated by the largest global magnitudes of turbulence intensity (at $z / H \leq 0.38$ ), found above the crests of the second ridges (crest 2). Lateral turbulence continues to overpower the longitudinal and vertical components nearest to the surface, as exemplified by the corresponding turbulence ratios above crest 2 . This may be attributed to the effects of lateral flow channelling caused by the horizontalplane flow separation around the first ridges and observed nearest to the surface of the inner valley regions. Results show that terrain effects on the near-surface turbulence of the flows above crest 2 are governed by the inflow characteristics of the second ridges and by their windward slopes. Inflows of the second ridges are mainly affected by the windward slopes of the first ridges, thus most affected by the $75^{\circ}$ geometry. However, the gentle inclination of the windward slope of the second ridge of this geometry tends to dampen the turbulence upstream from crest 2. Inversely, the smaller effects on the inflow for the $10^{\circ}$ geometry are amplified by the steepest windward slope of its second 
ridge. While not exhibiting the strongest influence on the inflow or the largest effects of the windward slopes, the combined effects of each generally result in maximal magnitudes of turbulence intensity above crest 2 being found for the $30^{\circ}$ geometry.

For the present experiments, the observed slope dependencies above each of the analysis positions are generally consistent amongst all studied turbulence properties. This is verified for the time-averaged flow properties and the peaks of energy of the spectral distributions at the lowest measurement height above each position $(z / H=0.15)$. However, the cause of the observed shifts of the frequencies of the spectral peaks relative to the undisturbed flow and reference data remains an open question. We can exclude the tilt of the coordinate system or the measurement set-ups as sources for these observations. The former was verified through flow coordinate transformations based on the average point-specific flow directions and the latter remained unchanged throughout the experiments, having yielded good agreement with the reference distributions for the undisturbed flow scenario.

\section{Conclusions}

Flows over three-dimensional symmetric isolated valleys of varying slope and with constant depth and width were characterized in a large boundary-layer wind tunnel. In order to ascertain the effects of the slopes on near-surface turbulence, flows above three distinct symmetric valley geometries were compared with undisturbed flows above flat terrain. For a model scale of 1:1000, the undisturbed flow data are in good agreement with neutrally stratified and moderately rough classed ABL flows at full scale.

Results show that the isolated valleys affect near-surface turbulence above the crests of both ridges and above the midpoint between the crests, with maximum impacts found downstream from the first ridges. Effects on the flows are generally dependent on the inclinations of the slopes of the ridges from which the valleys were built. Steeper slopes are found to generate the largest increases of turbulence compared with the undisturbed flow. Moreover, the inclinations of the windward slopes of both ridges are more influential on the flow perturbations than the respective leeside slopes. For all valleys, horizontal- and vertical-plane flow separation, driven by the presence of the first ridges, result in highly turbulent recirculation zones within the inner valleys. The lengths of the vertical-plane recirculation zones, roughly half the valley width for all geometries, are found to be independent of the slopes. Lateral turbulence dominated the near-surface flow characteristics within the recirculation zones, with maximum magnitudes found for steeper slopes of the first ridges. This is due to the three-dimensional geometries that allow the flow to transit around the sides of the ridges.

When comparable, the present results are consistent with previous findings reported in the literature. In particular, the data obtained above the crests of the first ridges show good agreement with trends extensively reported for flows over single hills or ridges. This demonstrates the reliability of the current experimental set-up and its ability to provide highquality turbulence statistics above downstream locations that have been less studied in the past. Thus, our data can be valuable in providing validation for numerical models and in improving the understanding of the effects of valleys on near-surface ABL flows.

Acknowledgements The authors wish to thank the German Research Foundation (DFG) for funding this research under project Grant LE2181/3-1. 
Funding Open Access funding enabled and organized by Projekt DEAL.

Open Access This article is licensed under a Creative Commons Attribution 4.0 International License, which permits use, sharing, adaptation, distribution and reproduction in any medium or format, as long as you give appropriate credit to the original author(s) and the source, provide a link to the Creative Commons licence, and indicate if changes were made. The images or other third party material in this article are included in the article's Creative Commons licence, unless indicated otherwise in a credit line to the material. If material is not included in the article's Creative Commons licence and your intended use is not permitted by statutory regulation or exceeds the permitted use, you will need to obtain permission directly from the copyright holder. To view a copy of this licence, visit http://creativecommons.org/licenses/by/4.0/.

\section{References}

Abdi DS, Bitsuamlak GT (2014) Wind flow simulations on idealized and real complex terrain using various turbulence models. Adv Eng Softw 75:30-41

Ayotte KW, Hughes DE (2004) Observations of boundary-layer wind-tunnel flow over isolated ridges of varying steepness and roughness. Boundary-Layer Meteorol 112:525-556

Bechmann A, Berg J, Courtney M, Ejsing Jorgensen H, Mann J, Sorensen NN (2009) The Bolund experiment: overview and background. Danmarks Tekniske Universitet, Riso National Laboratory for Sustainable Energy

Bechmann A, Sorensen NN, Berg J, Mann J, Réthoré PE (2011) The Bolund experiment, part II: blind comparison of microscale flow models. Boundary-Layer Meteorol 141:245-271

Blocken B, van der Hout A, Dekker J, Weiler O (2015) CFD simulation of wind flow over natural complex terrain: case study with validation by field measurements for Ria de Ferrol, Galicia, Spain. J Wind Eng Ind Aerodyn 147:43-57

Cao S, Tamura T (2007) Effects of roughness blocks on atmospheric boundary layer flow over a two-dimensional low hill with/without sudden roughness change. J Wind Eng Ind Aerodyn 95:679-695

Cao S, Wang T, Ge Y, Tamura T (2012) Numerical study on turbulent boundary layers over two-dimensional hills - effects of surface roughness and slopes. J Wind Eng Ind Aerodyn 104-106:342-349

Chaudhari A, Hellsten A, Hamalainen J (2016) Full-scale experimental validation of large-eddy simulation of wind flows over complex terrain: The Bolund hill. Adv Meteorol. https://doi.org/10.1155/2016/ 9232759

Conan B, Chaudhari A, Aubrun S, van Beeck J, Hamalainen J, Hellsten A (2016) Experimental and numerical modelling of flow over complex terrain: the Bolund hill. Boundary-Layer Meteorol 158:183-208

Counihan J (1975) Adiabatic atmospheric boundary layers: a review and analysis of data from the period 1880-1972. Atmos Env 9:871-905

Fernando HJS, Mann J, Palma JMLM, Lundquist JK, Barthelmie RJ, Belo-Pereira M, Brown WOJ, Chow FK, Gerz T, Hocut CM, Bell TM, Bodini N, Carney MB, Courtney MS, Creegan ED, Dimitrova R, Gomes S, Hagen M, Hyde JO, Kigle S, Krishnamurthy R, Lopes JC, Mazzaro L, Neher JMT, Menke R, Murphy P, Oswald L, Otarola-Bustos S, Pattantyus AK, Veiga Rodrigues C, Schady A, Sirin N, Spuler S, Svensson E, Tomaszewski J, Turner DD, van Neen L, Vasiljevic N, Vasallo D, Voss S, Wildmann N, Wang Y (2019) The Perdigão: peering into microscale details of mountain winds. Bull Am Meteorol Soc 100(5):799-819

Finnigan J, Ayotte K, Harman I, Katul G, Oldroyd H, Patton E, Poggi D, Ross A, Taylor P (2020) Boundary-layer flow over complex topography. Boundary-Layer Meteorol 177:247-313

Foken T (2008) Micrometeorology. Springer, Berlin

Garvey B, Castro IP, Wiggs G, Bullard J (2005) Measurements of flows over isolated valleys. BoundaryLayer Meteorol 117:417-446

Jackson PS, Hunt JCR (1975) Turbulent flow over a low hill. Q J R Meteorol Soc 101:929-955

Kaimal JC, Wyngaard JC, Izumi Y, Coté OR (1972) Spectral characteristics of surface-layer turbulence. Q J R Meteorol Soc 98:563-589

Kempf AM (2008) LES validation from experiments. Flow Turbul Combust 80:351-373

Letson F, Barthelmie RJ, Hu W, Pryor SC (2019) Characterizing wind gusts in complex terrain. Atmos Chem Phys 19:3797-3819

Liu Z, Ishihara T, Tanaka T, He X (2016) LES study of turbulent flows over a smooth 3-D hill and a smooth 2-D ridge. J Wind Eng Ind Aerodyn 153:1-12

Loureiro JBR, Pinho FT, Silva Freire AP (2007) Near-wall characterization of the flow over a two-dimensional steep smooth hill. Exp Fluids 42:441-457 
Lubitz WD, White BR (2007) Wind-tunnel and field investigation of the effect of local wind direction on speed-up over hills. J Wind Eng Ind Aerodyn 95:639-661

Mann J, Angelou N, Arnqvist J, Callies D, Cantero E, Chávez-Arroyo R, Courtney M, Cuxart J, Dellwik E, Gottschall J, Ivanell S, Kuhn P, Lea G, Matos JC, Veiga Rodrigues CM, Palma JMLM, Pauscher L, Peña A, Sanz Rodrigo J, Soderberg S, Vasiljevic N (2017) Complex terrain experiments in the New European Wind Atlas. Philos Trans R Soc 375(2091):20160101

Menke R, Vasiljevic N, Hansen KH, Hahmann AN, Mann J (2018) Does the wind turbine wake follow the topography? A multi-Lidar study in complex terrain. Wind Energy Sci 3:681-691

Menke R, Vasiljevic N, Mann J, Lundquist JK (2019) Characterization of flow recirculation zones at the perdigão site using multi-Lidar measurements. Atmos Chem Phys 19:2713-2723

Meroney RN (1990) Fluid dynamics of flow over hills/mountains-Insights obtained through physical modelling. In: Blumen W (ed) Atmospheric processes over complex terrain. Meteorological Monographs 23, American Meteorological Society, Boston, MA, pp 145-171

Pope SB (2000) Turbulent flows. Cambridge University Press, Cambridge

Simiu E, Scanlan RH (1986) Wind effects on structures: an introduction to wind engineering. Wiley, Hoboken

Snyder WH (1981) Guideline for modelling of atmospheric dispersion. Environmental Sciences Research Laboratory, Environmental Protection Agency Report EPA-600/8-81-009

Snyder WH, Khurshudyan LH, Nekrasov RE, Lawson RE, Thompson RS (1991) Flow and dispersion of pollutants within two-dimensional valleys. J Atmos Environ A25:1347-1375

Stull RB (2000) Meteorology for scientists and engineers. Brooks/Cole, California. ISBN:0534372147

Takahashi T, Ohtsu T, Yassin MF, Kato S, Murakami S (2002) Turbulence characteristics of wind over a hill with a rough surface. J Wind Eng Ind Aerodyn 90:1697-1706

Taylor GI (1938) The spectrum of turbulence. Proc Roy Soc Series A Math Phys Sci 164:476-490

Taylor PA, Teunissen HW (1987) The Askervein hill project: overview and background data. BoundaryLayer Meteorol 39:15-39

Teunissen HW, Shokr ME, Bowen AJ, Wood CJ, Green DWR (1987) The Askervein hill project: windtunnel simulations at three length scales. Boundary-Layer Meteorol 40:1-29

Vuorinen V, Chaudhari A, Keskinen JP (2015) Large-eddy simulation in a complex hill terrain enabled by a compact fractional step OpenFOAM solver. Adv Eng Softw 79:70-80. https://doi.org/10.1016/j.adven gsoft.2014.09.008

VDI-Verein Deutscher Ingenieure (2000) Environmental meteorology: physical modelling of flow and dispersion processes in the atmospheric boundary layer-application of wind-tunnels. Guideline VDI-3783-12

Yeow TS, Cuerva-Tejero A, Perez-Alvarez J (2015) Reproducing the Bolund experiment in wind-tunnel. Wind Energy 18:153-169

Publisher's Note Springer Nature remains neutral with regard to jurisdictional claims in published maps and institutional affiliations. 